\title{
INKJET PRINTING OF A GAS SENSOR
}

\author{
1David John DMONTE, ${ }^{1}$ Pavol ŠULY, ${ }^{1}$ Jan ANTOŠ, ${ }^{1}$ Pavel URBÁNEK, ${ }^{* 1} I$ vo KUŘITKA \\ ${ }^{1}$ Centre of Polymer Systems, Tomas Bata University in Zlin, Czech Republic, EU, dmonte@utb.cz
}

https://doi.org/10.37904/nanocon.2019.8574

\begin{abstract}
This contribution deals with preparation of functional interdigited flexible sensors for room temperature operation. The fabrication comprises the utilization of promising technology such as inkjet printing and the deposition of copper(II) acetylacetonate as a ultrathin sensing layer. The inks were prepared by dispersion formation in co-solvent system. The ink composition was developed on the basis of viscosity and surface tension optimization by the addition of polymeric steric surfactant. The printing process was optimized with the help of non-dimensional criteria. To obtain the best possible shape and resolution various parameters such as surface modification, thermal reduction atmosphere, annealing condition, setting of inkjet printer, Ink concentration and viscosity, sheet resistance were investigated. Printed pattern and motifs were characterized by profilometry, microscopy and by resistance measurement to further enhance the quality of printing. The sensitivity of the prepared sensors was demonstrated and studied by measuring the response to saturated vapors at room temperature to improve sensor performance by optimization. Obtained sensitivity of prepared sensors is very promising for detection of organic vapor detection at room temperature. Moreover, other big promising advantage of prepared sensors is their flexibility.
\end{abstract}

Keywords: Gas sensor, Inkjet printing, Room temperature

\section{INTRODUCTION}

The development of a low-cost flexible ambient gas sensor for organic vapors is vital, as it includes flammable gases such as acetone, which can be ignited by something as simple as static charge [1][2]. The scientific community has a lot of interesting development on the low-cost electronics and sensors as compared to traditional silicon based electronics, Inkjet printing plays a essential role here as it can be easily scaled up to meet industrial demands. Innate advantage of inkjet technology is the direct printing feature, high spatial resolution and the compatibility with many substrates.

Inkjet-printing is known technique for printing electronic and optoelectronic materials on a large scale for fabricating RFID tags, antennas [3][4][5][6] thin-film transistors (TFTs) [7][8], solar cells [9][10], light-emitting devices (LEDs) [11][12], display devices [13], tissue engineering [14][15] and sensors [16][17], Recently similar approaches have been taken by L. Siebert et al where they utilize a 3D- Printer to monitor acetone vapors using chemiresistive sensor array of $\mathrm{CuO} / \mathrm{Cu}_{2} \mathrm{O} / \mathrm{Cu}$ on glass substrates [18], Another closer approach recently is by L. Chen where they fabricate composite film by gravure technique for the detection of acetone [19].

This paper focuses on the development and the characterization of a printed acetone sensor, which records the sensitivity of quaternary copper complex deposited on inkjet printed electrodes. The main outcome of the proposed solution is low cost, flexible, simple ambient air and high-quality gas sensor. The inkjet printing technology allows for fast fabrication of prototypes on flexible substrates which can be designed as per the requirements.

\section{THE DEVELOPED SENSOR}

The device consists of a 1 centimeter polyimide substrate (UPILEX®-50 S) on which an interdigited structure has been printed by a FUJIFILM DMP-2800 series Dimatix Materials Printer using appropriate voltage and 
drop spacing. The silver dispersion (50-60 wt\%), nanoparticle based ink (Sigma Aldrich) was used and heated at $250{ }^{\circ} \mathrm{C}$ for 60 minutes. An ink of copper (II) acetylacetonate (Sigma Aldrich) has been prepared using ethylene gylcol with both surfactant and dispersant BYK® 348 and DISPERBYK® $190(1: 1, \mathrm{v} / \mathrm{v})$. They were supplied by BYK Additives and Instruments, a member of ALTANA, Wesel, Germany. The surfactant BYK® 348 is a polyether-modified siloxane and DISPERBYK® 190 is a high molecular weight block copolymer dispersant. The prepared Ink has been deposited successively using proper printing parameters, onto a silver electrode and heated at $200{ }^{\circ} \mathrm{C}$ for 60 minutes in $\mathrm{N}^{2}$ atmosphere. This can be seen in Figure 1 . The working principle of the sensor is by tracking the changes of electrical conductance of the copper(II) acetylacetonate layer due to the adsorption of gas molecules on its surface. These molecules act as donors or acceptors thus leading to a conductance variation.

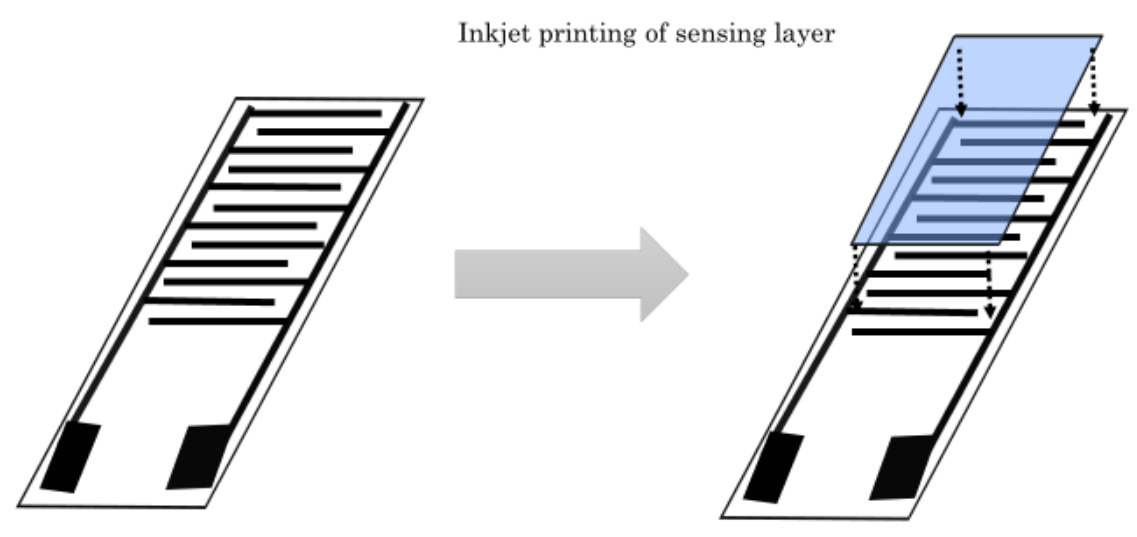

Figure 1 The sensing layer is inkjet printed on the silver electrodes

The experimental chamber adopted for the experiment is shown in Figure 2. The dynamic system consists of a heated u-pipe through which the carrier gas $\mathrm{N}_{2}$ flows, there is an insulating membrane where a flow of acetone can be injected manually. The carrier gas carries the gaseous elute through a small metal chamber which is vacuum sealed where the developed sensor is placed. The system is equipped with flowmeters and electrically controlled valves using proprietary software.

a)

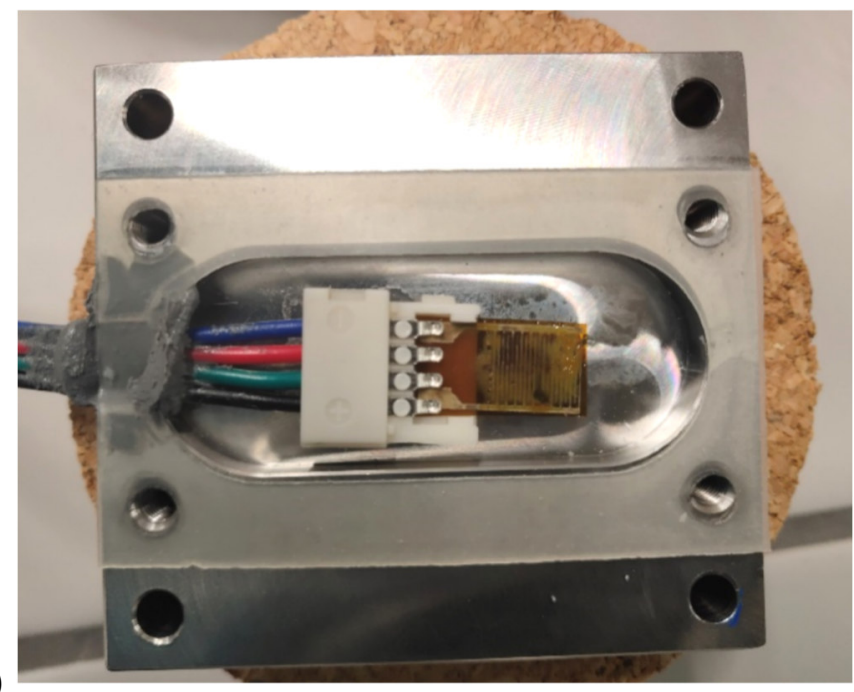

Figure 2a: The printed sensor is connected for resistance measurement in the chamber, Figure 2b: The inkjet printed sensor is subjected to bending, Device dimensions: $1.2 \mathrm{~cm}$ by $0.8 \mathrm{~cm}$ with a thickness of 200 micrometers. The Interdigit fingers width, length and track spacing. 


\section{EXPERIMENTAL RESULTS AND CONCLUSIONS}

The prepared ink I has the composition of $10 \mathrm{wt} \%$ copper(II) acetylacetonate in ethylene gylcol, along with 10 wt $\%$ BYK® 348 and $10 \mathrm{wt} \%$ DISPERBYK® 190. It has been characterized at $25 \mathrm{C}$. The surface tension was determined with a Krüss K100 force which uses the Wilhelmy plate method. The viscosity of dispersions was measured by a Ubbelohde type viscometer.

Table 1 Characterized data for Ink I sample

\begin{tabular}{|c|c|c|c|}
\hline & Viscosity & Density & Surface tension \\
\hline INK I & $34.8 \pm 0.5 \mathrm{mPa}-\mathrm{s}$ & $1.0696 \mathrm{~g} / \mathrm{cm}^{3}$ & $21.39 \pm 0.08 \mathrm{mN} / \mathrm{m}$ \\
\hline
\end{tabular}

Before each experiment, the chamber is flushed with $\mathrm{N}_{2}$ for a few minutes and it is checked for any possible gas leak. After having 100 percent gas flow of 200 milliliters/min. Controlled quantities of acetone have been injected to observe the response. Figure 3 shows the multiple response in the change of resistance in accordance with 50 microliters of acetone vapors injected periodically. Figure 4 similarly shows the repeated resistance change in response to multiple injections of 100 microliters of acetone vapors.

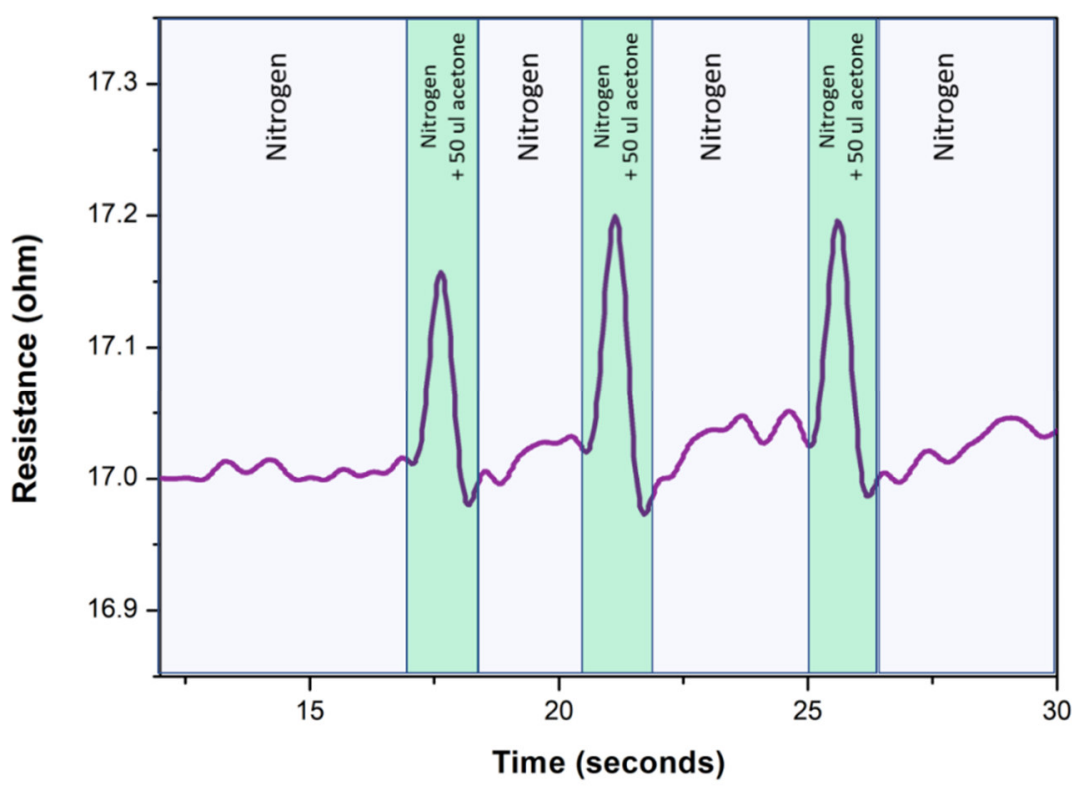

Figure 3 The observed sensing behavior for the vapors of $50 \mathrm{ul}$ of acetone at room temperature

The proposed mechanism here is, as the gas vapors interact with the sensing layer. Adsorbed molecular vapor ions, which are ionized preferentially at room temperature leads to a release of trapped electrons and neutralization of the holes of the copper (II) acetylacetonate. The decrease in the concentration of holes results in an increase of the resistance in the surface layer of copper (II) acetylacetonate. Meanwhile, the number of vapor ions absorbed on the surface is reduced leading to the decrease in the magnitude of the negative quasigate which further results in a decrease in conductivity [20]. Henceforth, a direct increase of the resistance with the increase of relative vapor is observed.

Since the portion of solid residuals from the additives in the ink composition is considerably high, their effect on sensor sensitivity and sensing behavior cannot be neglected. The surfactant (BYK-348) is a non-ionic compound polyether-modified siloxane which is not expected to contribute directly to the conduction mechanism. The other polymeric part of the dispersant (DISPERBYK 190) is a high molecular weight. block 
copolymer with carboxyl groups It can be expected that some carboxylic groups in the DISPERBYK co-polymer are neutralized and that polyelectrolyte-based humidity response may negligibly contribute to the sensing mechanism as well. Two reasons for negligence are, our sensor is fully printed on common plastic (PET polymer) and is kept at room temperature with hot vapors passing through the gas chamber at a high flow rate. Secondly, during the sintering process, most of the dispersants and surfactants are removed. The primary sensing mechanism is more likely to replace or outweigh other minor factors in a complex system.

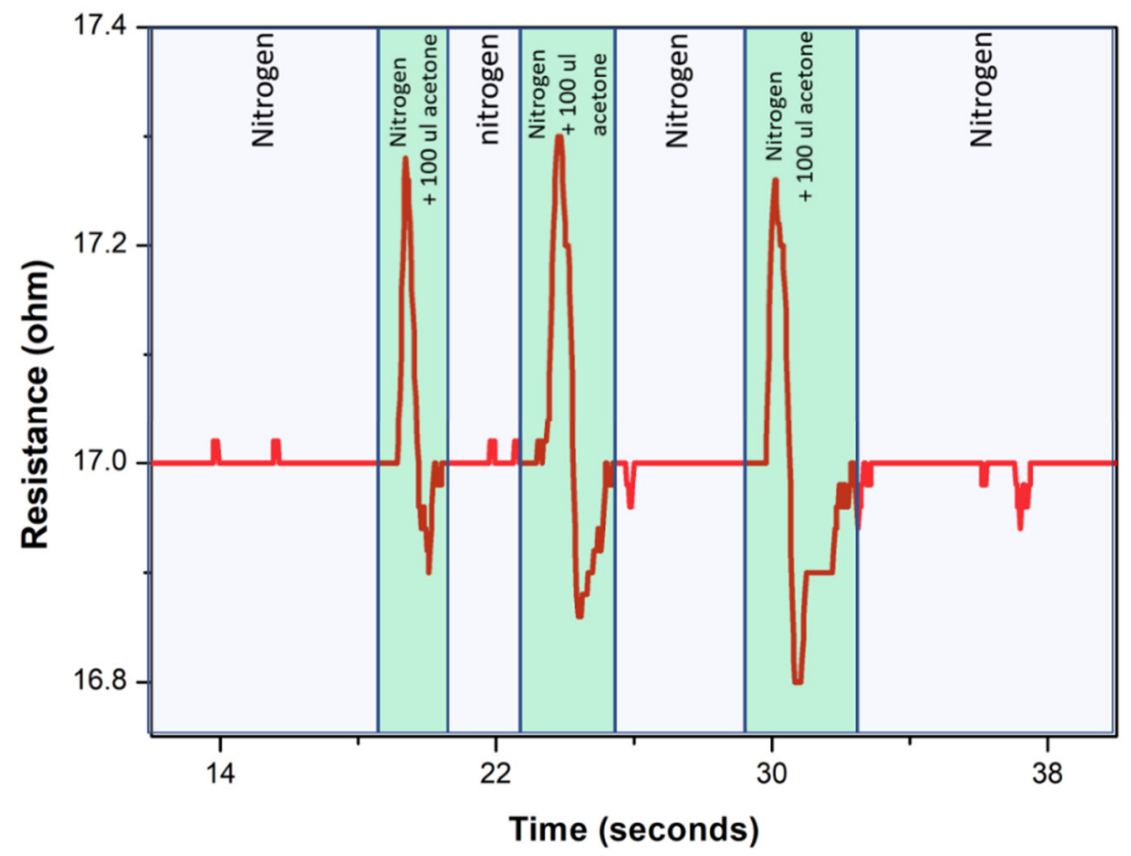

Figure 4 The recorded sensing behavior for the vapors of $100 \mathrm{ul}$ of acetone at room temperature

The experimental results obtained demonstrate the functionality of the developed sensor and encourage the sensing strategy. Future efforts will be dedicated to the device modeling and gas specificity among the development of further investigations.

\section{ACKNOWLEDGEMENTS}

This work was co-funded by the Ministry of Education, Youth and Sports of the Czech Republic (Grant No. LO 1504) and Internal Grant Agency of the Tomas Bata University in Zlin (Grant No. IGA/CPS/2019/007).

\section{REFERENCES}

[1] KOU, X., XIE, N., CHEN, F., WANG, T., GUO, L., WANG, C., ... LU, G. (2018). Superior acetone gas sensor based on electrospun $\mathrm{SnO} 2$ nanofibers by Rh doping. Sensors and Actuators, B: Chemical.

[2] Evaluating information. In: UK Solvents Industry Association. Guidance note 47 [online]. Version: 1. FLAMMABLE SOLVENTS AND THE HAZARD OF STATIC ELECTRICITY, 2007. Date: 10/2007. [viewed 2019-09-23]. Available from https://www.solvents.org.uk/wp-content/uploads/2015/02/SIA-Guidance-Note-47-FlammableSolvents-the-Hazard-of-Static-Electricity.pdf.

[3] NAYAK, L., MOHANTY, S., NAYAK, S. K., \& RAMADOSS, A. (2019). A review on inkjet printing of nanoparticle inks for flexible electronics. Journal of Materials Chemistry $C$.

[4] VIRTANEN, J., BJÖRNINEN, T., UKKONEN, L., \& SYDÄNHEIMO, L. (2010). Passive UHF inkjet-printed narrow line RFID tags. IEEE Antennas and Wireless Propagation Letters. 
[5] SHAO, B., CHEN, Q., AMIN, Y., HLLSTEDT, J., LIU, R., TENHUNEN, H., \& ZHENG, L. R. (2009). Processdependence of inkjet printed folded dipole antenna for $2.45 \mathrm{GHZ}$ RFID tags. European Conference on Antennas and Propagation, EuCAP 2009, Proceedings.

[6] ZHENG, L., RODRIGUEZ, S., ZHANG, L., SHAO, B., \& ZHENG, L. R. (2008). Design and implementation of a fully reconfigurable chipless RFID tag using inkjet printing technology. Proceedings - IEEE International Symposium on Circuits and Systems.

[7] SEKITANI, T., NOGUCHI, Y., ZSCHIESCHANG, U., KLAUK, H., \& SOMEYA, T. (2008). Organic transistors manufactured using inkjet technology with subfemtoliter accuracy. Proceedings of the National Academy of Sciences of the United States of America.

[8] OKIMOTO, H., TAKENOBU, T., YANAGI, K., MIYATA, Y., SHIMOTANI, H., KATAURA, H., \& IWASA, Y. (2010). Tunable carbon nanotube thin-film transistors produced exclusively via inkjet printing. Advanced Materials.

[9] EGGENHUISEN, T. M., GALAGAN, Y., BIEZEMANS, A. F. K. V., SLAATS, T. M. W. L., VOORTHUIJZEN, W. P., KOMMEREN, S., ... GROEN, W. A. (2015). High efficiency, fully inkjet printed organic solar cells with freedom of design. Journal of Materials Chemistry $A$.

[10] PENG, X., YUAN, J., SHEN, S., GAO, M., CHESMAN, A. S. R., YIN, H., ... ANGMO, D. (2017). Perovskite and Organic Solar Cells Fabricated by Inkjet Printing: Progress and Prospects. Advanced Functional Materials.

[11] CHANG, S. C., LIU, J., BHARATHAN, J., YANG, Y., ONOHARA, J., \& KIDO, J. (1999). Multicolor organic lightemitting diodes processed by hybrid inkjet printing. Advanced Materials.

[12] HAN, J., KO, D., PARK, M., ROH, J., JUNG, H., LEE, Y., ... LEE, C. (2016). Toward high resolution inkjet-printed quantum dot light-emitting diodes for next generation display. Digest of Technical Papers - SID International Symposium.

[13] RYU, G. S., KIM, J. S., JEONG, S. H., \& SONG, C. K. (2013). A printed OTFT-backplane for AMOLED display. Organic Electronics: Physics, Materials, Applications.

[14] CATROS, S., FRICAIN, J. C., GUILLOTIN, B., PIPPENGER, B., BAREILLE, R., REMY, M., ... GUILLEMOT, F. (2011). Laser-assisted bioprinting for creating on-demand patterns of human osteoprogenitor cells and nanohydroxyapatite. Biofabrication.

[15] BOLAND, T., XU, T., DAMON, B., \& CUI, X. (2006). Application of inkjet printing to tissue engineering. Biotechnology Journal.

[16] YANG, L., ZHANG, R., STAICULESCU, D., WONG, C. P., \& TENTZERIS, M. M. (2009). A novel conformal RFIDenabled module utilizing inkjet-printed antennas and carbon nanotubes for gas-detection applications. IEEE Antennas and Wireless Propagation Letters.

[17] SEEKAEW, Y., LOKAVEE, S., PHOKHARATKUL, D., WISITSORAAT, A., KERDCHAROEN, T., \& WONGCHOOSUK, C. (2014). Low-cost and flexible printed graphene-PEDOT:PSS gas sensor for ammonia detection. Organic Electronics: Physics, Materials, Applications.

[18] SIEBERT, L., LUPAN, O., MIRABELLI, M., ABABII, N., TERASA, M.-I., KAPS, S., ... ADELUNG, R. (2019). 3DPrinted Chemiresistive Sensor Array on Nanowire CuO/Cu 2 O/Cu Heterojunction Nets. ACS Applied Materials \& Interfaces, 11(28), 25508-25515.

[19] CHEN, L., HUANG, L., LIN, Y., SAI, L., CHANG, Q., SHI, W., \& CHEN, Q. (2018). Fully gravure-printed WO3/Ptdecorated rGO nanosheets composite film for detection of acetone. Sensors and Actuators, B: Chemical, 255, 1482-1490.

[20] HANSEN, B.J., KOUKLIN, N., LU, G., LIN, I.K., CHEN, J. and ZHANG, X., 2010. Transport, analyte detection, and opto-electronic response of p-type CuO nanowires. The Journal of Physical Chemistry C, 114(6), pp.24402447. 